\section{Gabapentin Differentially Modulate c-Fos Expression in Hypothalamus and Spinal Trigeminal Nucleus in Surgical Molar Extraction}

Jamil Ahsan Kazi', Ban Kahtan Ibrahim
Universiti Teknologi MARA

(UiTM), Jalan Hospital, Sungai

Buloh, Selangor, Malaysia

Correspondence: Kazi Ahsan Jamil, BDS, PhD, Associate Professor, Universiti Teknologi, MARA (UiTM) Faculty of Dentistry, Jalan Hospital, 47000 Sungai Buloh, Selangor, Malaysia. Tel: (+603) 61266511. e-mail: kazi@salam.uitm.edu.my

\begin{abstract}
The study on the efficacy of oral analgesics reported that no single class of drug is effective in post-surgical dental pain. Pain following removal of third molar is most commonly used and widely accepted acute pain model for assessing the analgesic effect of drugs in humans. Reports demonstrated that analgesic efficacy in the human dental model is highly predictive. The high incidence of false-negative findings in analgesic investigations hinders the process of molecular discovery. Molecular mechanism of post-surgical pain is not known. More importantly, the animal model for postoperative dental pain is not well established. In an attempt to discover an effective post-surgical dental pain blocker with acceptable side effects, it is essential to elucidate the molecular mechanism of post-operative dental pain. The present study investigated mandibular molars extraction in rat as an animal model for the post-operative dental pain in central nervous system. Using c-Fos immunohistochemistry, we demonstrated that pre administration of GBP $(150 \mathrm{mg} / \mathrm{kg}$. i.p) significantly $(\mathrm{p}<0.01)$ neutralized the surgical molar extraction induced c-Fos expression bilaterally in rat hypothalamus. Present results indicate that pain after surgical molar extraction might follow novel neural pathways therefore difficult to treat with existing anti-nociceptive drugs.
\end{abstract}

Key Words: surgical molar extraction, gabapentin, c-Fos, immunohistochemistry, rat, central nervous system.

\section{Introduction}

Pain after dental surgery still an unsolved issue and also an important factor in quality of life of patients at postsurgical periods. Surgery induces surgical stress and pain. This may result postoperatively morbidity and mortality. Surveys demonstrated that about $50-70 \%$ of patients experience moderate to severe pain after surgery indicating that despite the development of new drugs and improved analgesic techniques, postoperative pain remains still underevaluated and poorly treated. One important reason is the pathophysiology of postoperative pain still not known. To overcome clinical pain states, a mechanism based therapy may improve its management. Therefore it is now vital to reveal the molecular mechanism of postoperative pain. Surgery induced secondary hyperalgesia occurs in undamaged tissue adjacent to an injury responsible to develop secondary hyperalgesia and has been shown to depend only on Central sensitization.

Thus, once neuronal alterations that fully developed due to secondary hyperalgesia, their reversal by systemic administration of analgesic mostly difficult (1). Study in relative efficacy of oral analgesics reported that no single class of drug is effective in post- surgical dental pain. Moreover, there is association with gastrointestinal, cardiovascular and renal adverse effects and opioid is life threatening. Publication bias inflated the real picture of the efficacy of oral analgesics study in third molar extraction model. Studies reported that positive findings tend to be published more frequently than studies that report negative findings. $97 \%$ of the acute pain investigations study that yielded positive results clearly showed overestimation (3).

Reports on High incidence of false-negative findings in analgesic investigations mislead the process to reveal the molecular discovery of post-surgical dental pain mechanism. More importantly, less attention has been focused on the development of post-operative dental pain model and to understand the mechanism of postoperative acute dental Pain. Molecular mechanism of post-surgical dental pain is not known. Therefore, clinical results of the analgesics efficacy observed in human 3rd molar extraction model remains difficult to translate in molecular level. More importantly, the animal model for postoperative dental pain is not well established or difficult to generate (3).

In an attempt to discover an effective post surgical dental pain blocker with acceptable side effects, It is now essential to elucidate the molecular mechanism of postoperative dental pain.

Pain after dental surgery still remains an important factor in quality of life of patients at the early postoperative periods. Extraction of third molars activates peripheral as well as central pain pathways (4-7). Study in relative 
efficacy of oral analgesics reported that no single class of drug is effective in post-surgical dental pain. Moreover, there is association with gastrointestinal, cardiovascular and renal adverse effects and opioid is life threatening (3). Pain following removal of third molar model, a clinical research tool of postsurgical pain has been in widespread use for over 50 years, is well characterized, and is frequently used to investigate the efficacy of novel analgesic compounds (3).

Surgical characteristics of the third molar surgery allow subjects to experience moderate to severe postoperative pain (3).

In 1996 Brennan et. Al., in rat post-operative pain models (8) and in 2002 Kawamata et. Al., in Human volunteer models (2) reported that mechanisms of pain behavior following an incision are different from mechanisms described for inflammation, neurogenic, or neuropathic etiologics. Kazi et. al. (9), in a post-incisional rat model (20), demonstrated that paraventricular nucleus of the hypothalamus might be the neuromodulatory area in post-surgical pain (9).

Gabapentin (neurontin) a structural analogue of GABA has proven to be effective in reducing both postoperative and chronic pain, hyperalgesia, and allodynia in a wide range of animal models (10). GBP is well tolerated and shows very favorable side effects profile: lack of drug interaction and lack of potential for causing drug dependence (10). Reports suggest that gabapentin may exert its analgesic effect at both the spinal and supraspinal levels. The antihyperalgesic effect of gabapentin does not involveopiate pathways (11). Chronic administration does not lead to tolerance and morphine tolerance does not affect gabapentin effect on pain. GBP reduced the need for opioids in post-operative treatment, blocks and reverse the antinociceptive opioids tolerance and also prevent opiate withdrawal symptoms(11).

GBP has been reported as an anxiolytic drug in previous studies (11) Recently, several reports have indicated that GBP may indeed have a place in the treatment of postoperative pain (12). However, the exact molecular mechanism of action of GBP to block postoperative pain and stress is being investigated (9). GBP is able to block $\mathrm{Ca}^{2+}$ and $\mathrm{Na}++$ channels and open $\mathrm{K}$ channels thereby inhibiting the hyper-excitability of sensory neurons, thus ameliorating pain. GBP decreased the number of action potentials during depolarization in neuropathic pain. More importantly, the cellular and neuroanatomical functional target sites of GBP to block post-operative pain and stress is not known (12).

The immediate early genes (IEGs) encoded protein c-Fos is considered to be a transcription factor. c-Fos is expressed at low or undetectable levels in most cell types, but can be rapidly and transiently induced by many types of stimuli, including tissue trauma. Monitoring the nuclear expression of c-Fos, the protein product of the c-fos gene, is an established reliable anatomical technique for the functional mapping of the neuronal activity and can be helpful to examine the ability of neurons to react with changes in gene expression to external stimulation under physiological and pathological conditions (13-15). In this study, we used extraction of molars in the rats as a comparable model $(8,9)$ to study the GBP regulated neuromodulatory effects and its sites in post surgical dental pain process and also to compare with previously published results on post-incisional pain model (9).

\section{Material and Methods}

We obtained approval from the Institutional Animal Care and Use Committee for this study. All experimental procedures were carried out in accordance with CARE Universiti Teknologi MARA (UiTM), guidelines.

Male Sprague-Dawley rats (180-200 g), Animals were housed in groups of two, and had free access to food and water at all times. Animals were on a fixed $12 \mathrm{~h}$ lightdark cycle. In order to minimize stress, all animals were brought to the laboratory and acclimatized once daily for at least five days by exposure to the general handling and anaesthesia procedures.

\section{Surgical Procedures}

The surgical procedure was based on that described previously (9). Briefly, rats were anaesthetized with intraperitoneal injection of sodium pentobarbital $(50 \mathrm{mg} /$ $\mathrm{kg}$ ). Lower $1 \mathrm{st}$ and $2 \mathrm{nd}$ molars of either side were surgically extracted. Sham extraction (intact) was performed by opening of the mouth for $5 \mathrm{~min}$. intact rats received no gabapentin treatment. Gentle pressure with surgical cotton was applied for hemostasis.

\section{Application of Gabapentin in the Experimental and Control Groups}

GBP was parched from Sigma and dissolved in 0.9\% saline. Six rats per group were used in all experiments Control: Intact (no extraction, only received i.p., injection of normal saline. The mouth was kept open for 5 min. 2 . Molar extraction: mandibular 1st and 2nd molars of either side were surgically extracted. Gentle pressure with surgical cotton was applied for hemostasis. 3. Molar Extraction plus GBPadministration: A single intraperitoneal injection (i.p.) of GBP $(150 \mathrm{mg} / \mathrm{kg})$ dissolve in $0.9 \%$ saline was given 20 minutes before tooth extraction. In all cases the dosing volume was $1 \mathrm{~mL}$. Rats of all groups were kept under deep anesthesia until sacrifice to minimize the pain perception.

\section{Perfusion and Tissue Collection}

At 90 minutes after tooth extraction the deeply 
anesthetized rats were perfused transcardially with heparinized physiological saline, followed by $4 \%$ paraformaldehyde in

0.1 M phosphate buffer, $\mathrm{pH}$ 7.4. The brains were cryoprotected. Serial $40 \mu \mathrm{m}$ thick sections were cut with a freezing microtome.

\section{Immunohistochemistry}

The immunocytochemical detection of c-Fos protein was performed using the peroxidase-antiperoxidase (PAP) detection protocol (9). Free-floating sections were then incubated at $4^{\circ}$ with rabbit antibody to c-Fos protein (Santa Cruz Biotechnology Inc., Santa Cruz, CA) diluted 1:4,000. Then incubated in a 1:2,000 dilution of goat anti-rabbit lgG (E-Y Laboratories Inc., San Mateo, CA) at $4{ }^{\circ}$ and followed by the tertiary antibody, peroxidase-antiperoxidase (PAP) in a $1: 2,000$ dilution at $4^{\circ}$. The primary, secondary and tertiary antibodies were diluted to appropriate concentrations in $0.3 \%$ bovine serum albumin and $1 \%$ normal goat serum and $0.05 \%$ sodium azide. The DAB method for visualization of peroxidase was used (9). After the final rinses the sections were mounted onto gelatin-chrome alum-coated glass slides, air-dried, dehydrated with ethanol, cleared in xylene, and coverslipped. The specificity of the immune reaction was assessed by omitting the primary antibody in which no specific immunostaining was detected.

The sections were analyzed under a microscope and the labeled c-Fos positive neurons per section were counted. Counts were obtained from a 1 in 2 series of sections and 6 sections per animal were used. Then, the mean number of c-Fos positive neurons ( \pm standard deviation: S. D.) for each time point was calculated. The statistical analysis was performed using a paired $t$ test and differences at $p<0.001$ were considered significant.

\section{Results}

\section{PVN of the Hypothalamus}

Molar Extraction: In this study at 90 minutes after the surgical tooth extraction, a robust increase in Fos expression was found bilaterally in the PVN of the hypothalamus (9).

As shown in Figure 1, compare to intact the higher numbers of densely labelled c-Fos positive neurons were observed bilaterally in the PVN at 90 minutes after surgical tooth extraction. The semi-quantitative analysis of the
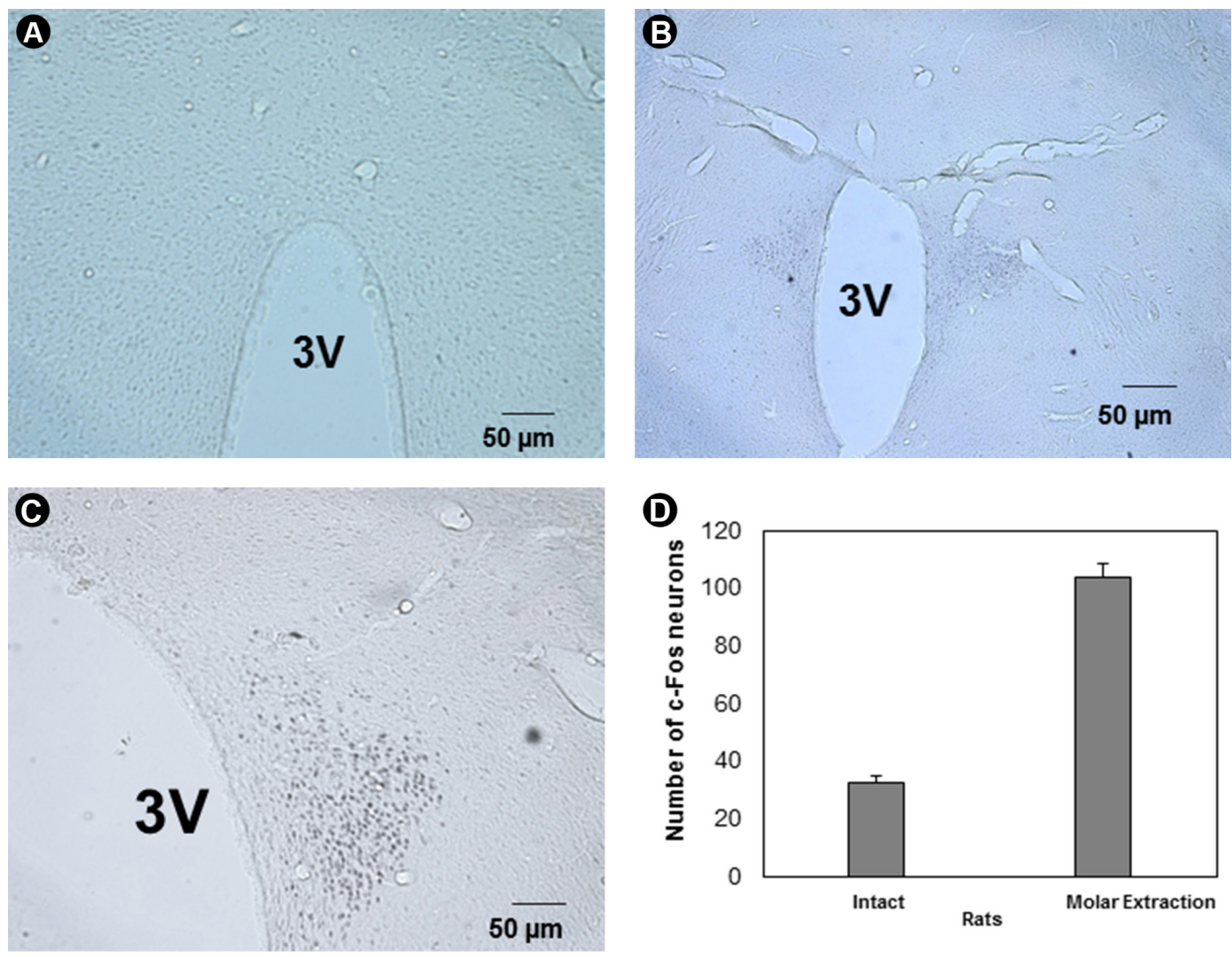

Figure 1. Photomicrographs showing the expression of c-Fos protein in the paraventicular nucleus of the hypothalamus after molars extraction. Compared with the intact rats (A), a significantly increased number of c-Fos positive neurons is observed at 90 minutes after molar extraction (B). (C) is the higher magnification of (B). Scale bar, $50 \mu \mathrm{m}$. (D) A graphic showing the semi-quantitative analysis of c-Fos positive neurons in the PVN of the rats after molar extraction. Compared with the intact rats a significantly increased number of c-Fos positive neurons is observed at 90 minutes after molar extraction $(\mathrm{p}<0.001)$. Nuclei immunoreactive for c-Fos protein appear as black staining. Scale bar, $50 \mu \mathrm{m}$. 
number of the c-Fos-positive nerve somata per section revealed $52 \pm 9$ in the right side and $61 \pm 11$ in the left side of the PVN nuclei in the intact rats. Compared with the intact rats $(p<0.001)$, the number of $c-$ Fos immunoreactive cell bodies was $98 \pm 17$ per section in the left side and $97 \pm 19$ per section in the right one. In the PVN, surgical tooth extraction increased Fos expression by 4 folds. These findings are consistent with the previously published report which demonstrated surgical paw incision induced increases in the number of c-Fos positive neurons in the bilateral PVN of the hypothalamus (9).

Molar Extraction plus GBP administration: As shown in Figure 2, Fos positive cells induced by surgical tooth extraction (Fig. 2A) in the PVN were significantly suppressed when rats were pre-treated with the administration of GBP $(150 \mathrm{mg} / \mathrm{kg}$, i.p.) 20 minutes prior to paw surgery (Fig. 2A and 2B). In the PVN at 90 minutes after surgical tooth extraction the number of c-Fos immunoreactive cell bodies was $98 \pm 3$ in the intact and $20 \pm 2.9$ in the GBP pretreated rats per section $(p<0.001)$ (Fig. 2B). These results suggested the neutralizing effect of GBP pre-treatment on molar extraction induced activation of PVN.

\section{Spinal Trigeminal Nucleus}

Molar Extraction: As shown in Figure 3, surgical tooth extraction showed significant increase in the number of c-Fos immunostained neurons in the spinal trigeminal nucleus as compared to intact rats (Fig. 3A, intact and Fig. 3B, GBP treated). This finding is consistent with the previously published report (10).

Molar Extraction plus GBP administration: As shown in Figure $3 \mathrm{C}$ rats pre-treated with GBP $(150 \mathrm{mg} / \mathrm{kg}$, i.p.) 20 minutes before surgical tooth extraction did not neutralize the surgical tooth extraction induced increased in c-Fos expression in the spinal trigeminal nucleus. Figure $3 \mathrm{C}$, shows semi-quantitative analysis of the number of c-Fos protein-like immunoreactive nerve cell bodies in the spinal trigeminal nucleus in intact, after surgical tooth extraction and after administration (i.p.) of GBP ( $150 \mathrm{mg} / \mathrm{kg}$, i.p.) 20 minutes before molar extraction. The number of the c-Fos positive neurons was $3 \pm 0$ in the intact, $19 \pm 2$ in the surgical tooth extraction and $18 \pm 1$ in the GBP treated rats per section $(p<0.001)$.

\section{Discussion}

The result of this study demonstrated that the surgical tooth extraction induced increase in c-Fos expression in the paraventicular nucleus of the hypothalamus was attenuated by a single dose ( $150 \mathrm{mg} / \mathrm{kg}$, i.p.) of GBP given $20 \mathrm{~min}$. before surgical tooth extraction. In addition, GBP pretreatment did not attenuate the tooth extraction induced elevated c-Fos like immunoreactivity in the spinal trigeminal nucleus. To our knowledge, the present study demonstrated for the first time the neuromodulatory functional sites of GBP in post-surgical tooth extraction.

Gabapentin (Neurontin) a structural analogue of GABA has proven to be effective in reducing pain, hyperalgesia, and allodynia in a wide range of animal models including postoperative pain (10) and anxiety (17). A recent report demonstrated that gabapentin administered was associated with a significant reduction in the requirement for regional analgesia (epidural analgesia) there were also significant improvements in postoperative pain scores and patient satisfaction with less postoperative motor block (17). GBP

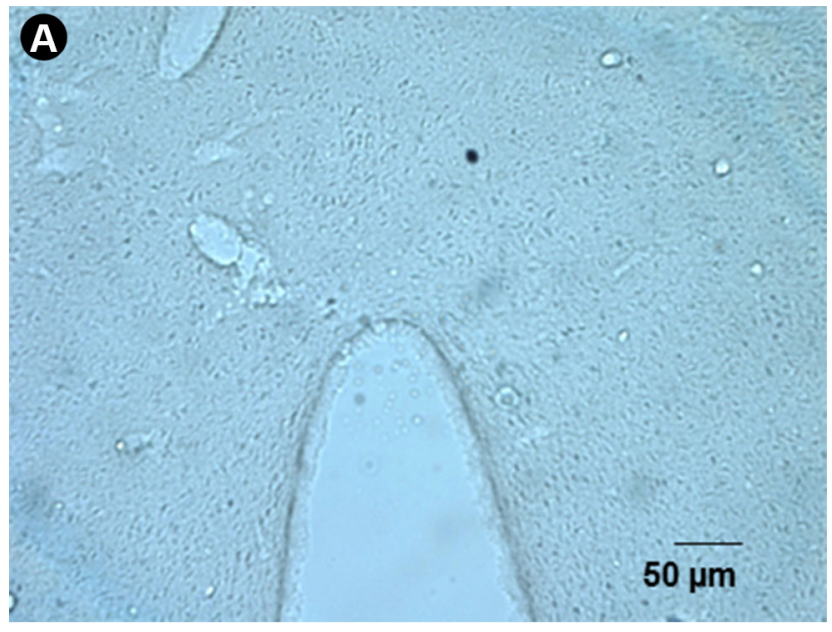

\section{B GBP Pre-treatment}

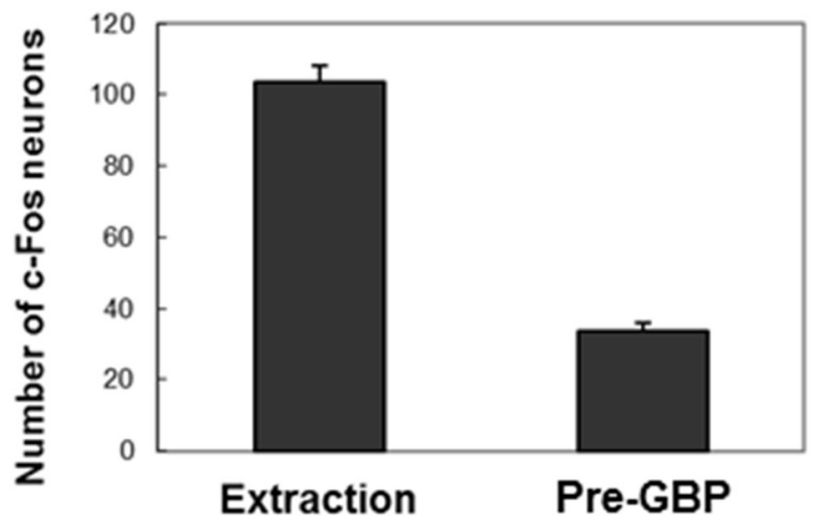

Figue 2. Photomicrographs showing the expression of c-Fos protein in the paraventicular nucleus of the hypothalamus after surgical extraction of molars. Compared with the molar extraction rats (1B and 1C), the elevated c-Fos expression induced by molar extraction in the PVN is completely attenuated in rats pre-treated with GBP $(150 \mathrm{mg} / \mathrm{kg}$, i.p.) (A and B). Scale bar, $50 \mu \mathrm{m}$. 
binds to the $\alpha 2 \delta$ subunit of calcium channels, a subunit
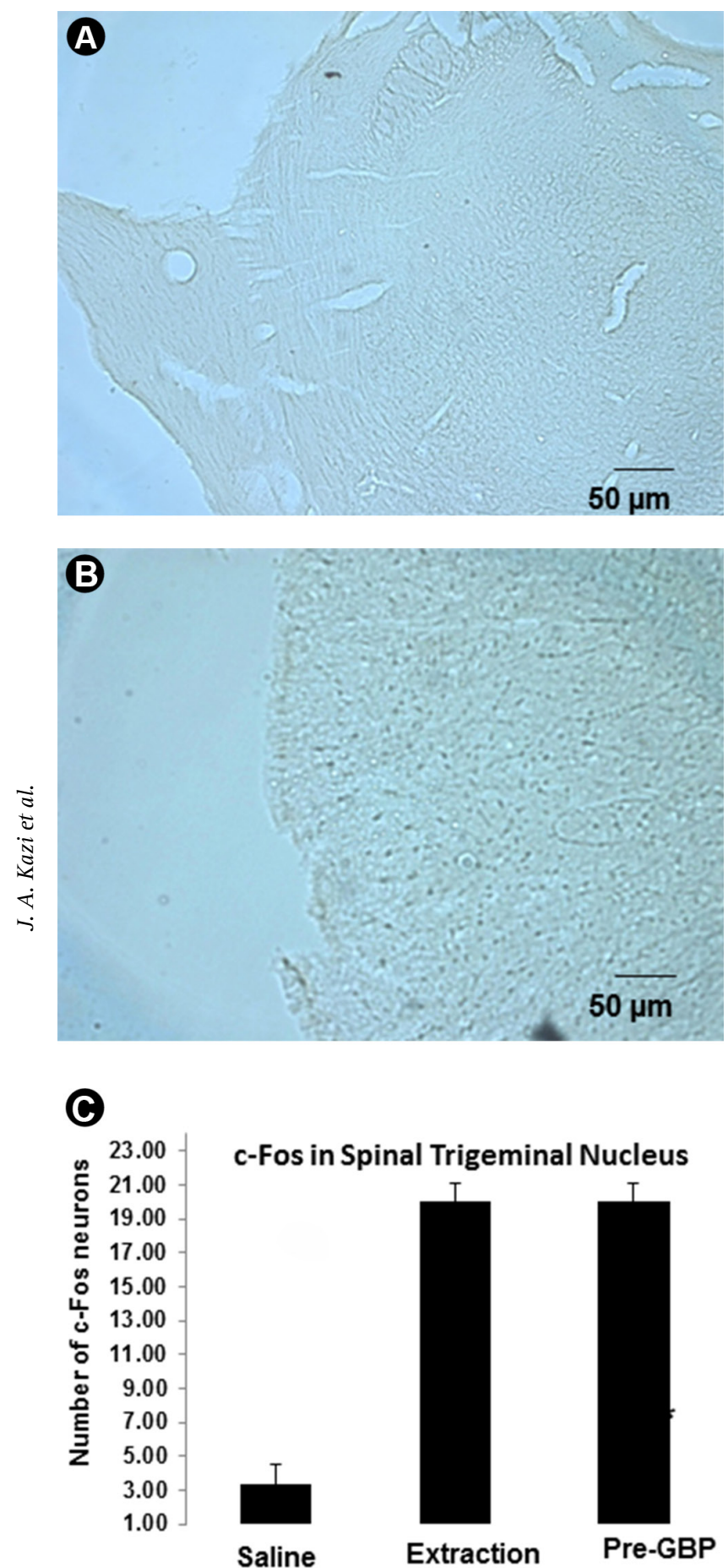

Figure 3. Photomicrographs showing the expression of c-Fos protein in the spinal trigeminal nucleus. Compared with the intact rats (A), molar extraction induced elevated c-Fos expression by in the spinal trigeminal nucleus (B). Nuclei immunoreactive for c- Fos protein appear as black staining. Scale bar, $50 \mu \mathrm{m}$. (C), A graphic showing the semi-quantitative analysis of c-Fos positive neurons in the spinal trigeminal nucleus. Compared with intact rats the molar extraction induced increased in c-Fos expression in the spinal trigeminal nucleus. Rats pre-treated with GBP before molar extraction could not attenuate the increased c-Fos expression induced by molar extraction $(\mathrm{p}<0.001)$. ubiquitous to all voltage-dependent calcium channels (VDCCs). Report demonstrated that preoperative GBP decreased anxiety and improved early functional recovery from knee surgery (17).

The present study demonstrated that c-Fos like immunoreactive neurons were significantly increased in the PVN of the hypothalamus. This increase in c-Fos expression in PVN was attenuated by the administration of GBP (150 mg/kg, i.p.) 20 minutes prior to molar extraction. This study indicate that pre administration of GBP antagonize the surgical molar extraction induced activation of the PVN. This result is in accordance with our previous report on rat incisional pain model (9). Several lines of evidence suggest that the hypothalamus is involved in trigeminal pain processing (18).

However, further studies are needed to explain the underlying mechanisms of the GBP induced attenuation of c-Fos in the PVN after surgical molar extraction.

Fos dimerize with Jun family and form transcription factor called activator protein-1 (AP-1). AP-1 complexes interact with a consensus sequence TGACTCA in the regulatory regions of target genes and stimulate or repress transcription of the target genes thereby subserving long-term changes in cellular function. c-Fos induction happened at least 5 regulatory signal transduction pathways. Therefore in our study, extraction induced induction and then GBP induced inhibition of c-Fos protein in the PVN of the molar extracted rats indicated the GBP regulated unknown gene expression occurred in the PVN through an unknown circuit (15)

Present study also demonstrated that GBP administration 20 minutes before surgical molar extraction didn't not attenuated the extraction induced c-Fos like immunoreactive neurons in the spinal trigeminal nucleus. c-fos gene contains several cis-acting elements, that could confer variety of trans-synaptic signals via interdependent signal transduction pathways (e.g., PKA, PKC, CAM kinase and MAP kinase e.t.c.). However it is noteworthy to mention that, c-Fos induction does not provide evidence for the activated specific target genes in the certain cell type of interest. Therefore, further study is required to reveal this unknown gene involved in the c-Fos activated neurons. The results of this study strongly indicated that, to neutralize the molar extraction induced activation of PVN an unknown factors (gene) in the c-Fos activated neurons in the spinal trigeminal nucleus played a crucial role. Therefore, to reveal molar extraction induced novel neuronal circuit further study is essential to identify the gene (s) in c-Fos induced neurons in the PVN and in the spinal trigeminal nucleus. Since c-Fos protein has extralong half lives, we therefore speculated that neurons in the spinal trigeminal nucleus remain active in order to 
maintain the expression of the unknown target genes through an unknown circuit to attenuate c-Fos expression in the PVN (15).

In this regards, a recent report showed that gabapentin inhibited substance $P$ facilitated release of the sensory neurotransmitter glutamate in an in vitro preparation of the spinal trigeminal nucleus of the rat (19). Another recent report observed the existence of bilateral descending hypothalamic projections to the spinal trigeminal nucleus (20), Moreover, studies reported that a substantial number of spinal trigeminal nucleus neurons directly send their axons to hypothalamic regions (21). Report demonstrated that substance $P$ receptor like immunoreactivity (SPRLI) neurons projected to paraventricular hypothalamic nucleus. The hypothalamus a key player in nociceptive processing and modulated the perception of trigeminal pain $(20,21)$. Tooth pulp stimulation showed strongest effect in the hypothalamus, significantly up-regulated mRNA levels for the neuropeptides: galanin (GAL), vasopressin (AVP), oxytocin (OT), substance $P(S P)$, vasoactive intestinal peptide (VIP), endomorphin-2 (EM-2), and opioid receptors: MOR, DOR and KOR (22). Oxytocin OX When centrally applied and vasopressin (VP), either centrally applied or microinjected into the spinal trigeminal nucleus (23), reduced the amplitude of trigeminal reflex induced by noxious tooth pulp stimulation. OX when systemically applied attenuated electrical whisker pad stimulation- induced pain-vocalization in newborn rats. Oxytocin-induced analgesia in mice and vasopressininduced analgesia in rat are mediated by the vasopressin$1 \mathrm{~A}$ receptor $(\mathrm{V} 1 \mathrm{aR}), \mathrm{V} 1 \mathrm{aR}$ mRNA was detected in many brain areas, including the spinal nucleus of the trigeminal tract (23). Another report demonstrated that this OX mechanism of pain modulation only involved opiate pathway (24). More importantly, antinocipeptive effect of gabapentin does not involve opiate pathways $(10,11)$. However, the effect of GBP on vasopressin (VP) and oxytocin (OX) regulation not known, GBP might exert its effect on VP and OX trans-synaptically (21). It cannot be ruled out that GBP might have exerted its effect on VP and OX trans-synaptically (24) through an unknown non-opioid circuit or GBP might have neuromodulated novel signaling molecules of pain regulating circuit without involving opiate pathways (19). Further study is warranted to reveal the neurochemistry of the molar extraction induced c-Fos containing neurons.

Thus, our present study suggests that GBP might differentially modulate c-Fos expression in surgical tooth extraction in the PVN and in spinal trigeminal nucleus $(21,25)$. We therefore speculated that the increased in c-Fos expression observed in our study at spinal trigeminal nucleus which was not attenuated by gabapentin pre- administration indicated the trans-synaptic functional activation of gabapentin on spinal antinoception system $(21,22,25)$. Analyzing the above reports the results of this study speculate the existence of novel bi-directional neuromodulatory circuit between hypothalamus and spinal trigeminal nucleus involved in the regulation of surgical molar extraction. Therefore, further study is needed to reveal the nature of this GBP regulated c-Fos like immunoreactive neurons in the PVN and the spinal trigeminal nucleus observed in present study. Present result also indicates that pain after surgical molar extraction might follow novel bi-directional neuromodulatory pathways therefore difficult to treat with existing antinociceptive $(21,22)$.

The results obtained here will to be useful for further studies to gain more insights into the mechanisms underlying the antinociceptive and anxiolytic actions of after dental surgery.

These results also are consistent with our previous published report on rat incisional model (9). Therefore, this study proposes that tooth extraction in rat validate as an experimental animal model for post-surgical dental pain study.

As it has been proved that, number of different challenges involved through multiple signal transduction pathways in the induction c-Fos expression (23). Finally, our present findings indicate that GBP may differentially modulate c-Fos expression in surgical molar extraction (antagonising the PVN activity whereas stimulating the spinal trigeminal system) and also provide some clue to investigate whether GBP exert its action simultaneously through multiple separate pathways in neuromodulation $(9,16,22,23)$ after surgical tooth extraction. This study furthers our understanding of the mechanism of acute post-surgical dental pain.

\section{Resumo}

0 estudo da eficácia relativa dos analgésicos orais relatou que nenhuma classe única de fármaco é eficaz na dor pós-cirúrgica dental. A dor após a remoção do terceiro molar é o modelo de dor aguda mais comumente usado e amplamente aceito para avaliar o efeito analgésico de drogas em seres humanos. Os relatos demonstraram que a eficácia analgésica no modelo dental humano é altamente preditiva. A alta incidência de achados falso-negativos em investigações analgésicas dificulta o processo de descoberta molecular. 0 mecanismo molecular da dor pós-cirúrgica não é conhecido. Mais importante ainda, o modelo animal para a dor pós-operatória não está bem estabelecido. Numa tentativa de descobrir um bloqueador de dor dental pós-cirúrgico eficaz com efeitos secundários aceitáveis, é essencial elucidar o mecanismo molecular da dor pósoperatória dental. Neste estudo investigamos a extração de molares inferiores de ratos como modelo animal para a dor pós-operatória no sistema nervoso central. Utilizando análise imunohistoquímica de c-Fos, demonstrou-se que a administração prévia de GBP $(150 \mathrm{mg} / \mathrm{kg}$ i.p) significativamente $(p<0,01)$ neutralizou a expressão c-Fos induzida por extração molar cirúrgica bilateralmente no hipotálamo de rato. Os resultados indicam que a dor após a extração molar cirúrgica pode 
seguir novas vias neurais, portanto, dificil tratar com as drogas antinociceptivas existentes.

\section{Acknowlegements}

This work was supported by a grant form Penyelidikan Dana Pembudayaan Penyelidikan (RAGS), University Teknologi MARA (Grant \#600-RM|/RAGS 5/3 (124/2012).

\section{References}

1. Chauvin M. Relieving post-operative pain. Presse Med 1999;28:203211.

2. Kawamata $M$, Takahashi T, Kozuka $Y$, Nawa $Y$, Nishikawa $K$, Narimatsu $E$, et al. Experimental incision-induced pain in human skin: effects of systemic lidocaine on flare formation and hyperalgesia. Pain 2002;100:77-89.

3. Cooper SA, Desjardins PJ. The value of the dental impaction pain model in drug development. Methods Mol Biol 2010;617:175-190.

4. Badral B, Davies AJ, Kim YH, Ahn JS, Hong SD, Chung G, et al.. Pain fiber anesthetic reduces brainstem Fos after tooth extraction. J Dent Res 2013;92:1005-1010.

5. Dworkin RH, Turk DC, Peirce-Sandner S, Baron R, Bellamy N, Burke LB, et al. Research design considerations for confirmatory chronic pain clinical trials: IMMPACT recommendations. PAIN ${ }^{\circledR 2} 2010 ; 149: 177-193$.

6. Korn S, Vassil TC, Kotey PN, Fricke JR. Comparison of rofecoxib and oxycodone plus acetaminophen in the treatment of acute pain: a randomized, double-blind, placebo-controlled study in patients with moderate to severe postoperative pain in the third molar extraction model. Clin Ther 2004; 26:769-778.

7. Sessle B.J. Acute and chronic craniofacial pain: brainstem mechanisms of nociceptive transmission and neuroplasticity, and their clinical correlates, Crit Rev Oral Biol Med 2000;11:57-91.

8. Brennan TJ, Vandermeulen EP, Gebhart GF Characterization of a rat model of incisional pain. Pain 1996;64:493-501.

9. Kazi JA, Gee CF.Effect of gabapentin on c-Fos expression in the CNS after paw surgery in rats. J Mol Neurosci 2007;32:228-234.

10. Gilron I. Is gabapentin a "Broad-spectrum" analgesic? Anesthesiology 2002;97:537-539.

11. Gilron I, Biederman J, Jhamandas K, Hong M. Gabapentin blocks and reverses antinociceptive morphine tolerance in the rat paw-pressure and tail-flick tests. Anesthesiology 2003;98:1288-1292.

12. Dirks J, Fredensborg BB, Christensen D, Fomsgaard JS, Flyger H, Dahl JB. A randomized study of the effects of single-dose gabapentin versus placebo on postoperative pain and morphine consumption after mastectomy. Anesthesiology 2002;97:560-564.
13. Pandey CK, Sahay S, Gupta D, Ambesh SP, Singh RB, Raza M, et al.. Preemptive gabapentin decreases postoperative pain after lumbar discoidectomy. Can J Anesth 2004;51:986-989.

14. Suzuki $R$, RahmanW, Rygh $\sqcup$, Webber M, Hunt SP, Dickenson AH. Spinal- supraspinal serotonergic circuits regulating neuropathic pain and its treatment with gabapentin. Pain 2005;117:292-303.

15. Kovács KJ. c-Fos as a transcription factor: a stressful (re)view from a functional map. Neurochem Int 1998;33:287-297

16. Sabino MA, Honore $P$, Rogers SD, Mach DB, Luger NM, Mantyh $\mathrm{PW}$. Tooth extraction-induced internalization of the substance $\mathrm{P}$ receptor in trigeminal nucleus and spinal cord neurons: imaging the neurochemistry of dental pain. Pain 2002;95:175-186.

17. Menigaux C, Adam F, Guignard B, Sessler DI, Chauvin M. Preoperative gabapentin decreases anxiety and improves early functional recovery from knee surgery. Anesth Analg 2005;100:1394-1399.

18. Holle D, Katsarava Z, Obermann M (2011)The hypothalamus: specific or nonspecific role in the pathophysiology of trigeminal autonomic cephalalgias? Curr Pain Headache Rep 15:101-107.

19. Maneuf YP, Blake $R$, Andrews NA, McKnight AT.Reduction by gabapentin of $\mathrm{K}+-$ evoked release of [3H]-glutamate from the caudal trigeminal nucleus of the streptozotocin-treated rat. Br J Pharmacol 2004;141:574-579

20. Abdallah K, Artola A, Monconduit L, Dallel R, Luccarini P., Bilateral descending hypothalamic projections to the spinal trigeminal nucleus caudalis in rats. PLoS One. 2013;8:73022.

21. Li JL, Kaneko T, Shigemoto R, Mizuno N. Distribution of trigeminohypothalamic and spinohypothalamic tract neurons displaying substance $\mathrm{P}$ receptor-like immunoreactivity in the rat. J Comp Neurol 1997;378:508-521.

22. Kovács KJ. c-Fos as a transcription factor: a stressful (re)view from a functional map. Neurochem Int 1998;33:287-297.

23. Zubrzycka M, Szemraj J, Janecka A, Effect of tooth pulp and periaqueductal central gray stimulation on the expression of genes encoding the selected neuropeptides and opioid receptors in the mesencephalon, hypothalamus and thalamus in rats. Brain Res 2011;1382:19-28.

24. Ostrowski NL, Lolait SJ, Bradley DJ, O'Carroll AM, Brownstein MJ, Young WS 3rd. Distribution of V1a and V2 vasopressin receptor messenger ribonucleic acids in rat liver, kidney, pituitary and brain. Endocrinology 1992:131:533-535

25. Condés-Lara M, Rojas-Piloni G, Martínez-Lorenzana G, LópezHidalgo $M$, Rodríguez-Jiménez J. Hypothalamo spinal oxytocinergic antinociception is mediated by GABAergic and opiate neurons that reduce $\mathrm{A}$-delta and $\mathrm{C}$ fiber primary afferent excitation of spinal cord cells. Brain Res 2009;1247:38-49.
Received April 14, 2016 Accepted September 1, 2016 